In September 2015 a female tiger was detected by a camera trap in the core area of Kawal Tiger Reserve, and in December 2015 a male tiger was similarly photographed in the same area. In March 2016 the tigress was seen with four cubs in nearby forests. WCS India and partners have been closely monitoring these new recruits into the population, particularly as mortality rates of tiger cubs are high. As of December 2016 two of the cubs have survived and remain in the tigress's territory, and one has dispersed to a new territory and is still being monitored by WCS India and the Forest Department. The remaining cub and the mother have not been seen in this territory since November 2016.

For more than a decade reproducing tigers have not been recorded in this area, but strict protection, combined with stakeholder involvement, has resulted in immigration and reproduction within the Reserve. Close monitoring of the immigrant tigers will continue. With $900 \mathrm{~km}^{2}$ of core habitat, and a 1,100 $\mathrm{km}^{2}$ buffer zone, Kawal Tiger Reserve has potential to be an important tiger population in this landscape. With continued protection, this protected area can serve as an example of how effective threat mitigation can assist in species population recovery and, ultimately, in increasing global tiger numbers.

ImRAN SIDDIQUi and DIVYA VASUdeV Wildlife Conservation Society India Program, Bengaluru, India

E-mailvasudev.divya@gmail.com

\section{Reintroduced northern bald ibises from Spain reach Morocco}

The northern bald ibis Geronticus eremita is one of the few Critically Endangered bird species whose breeding range is confined to the Western Palearctic. At present two disjunct natural populations are known: in Morocco, and in Turkey and Syria. In Morocco the population consisted of c. 116 breeding pairs in 2015. In the Middle East the population has suffered a long-term decline; in Turkey there is a semicaptive colony, and in Syria a small colony was discovered in 2002 (Serra et al., 2004, Oryx, 38, 106-108), with birds migrating to Ethiopia (Lindsell et al., 2009, Oryx, 43, 329-335). In Europe the species became extinct c. 400 years ago, although it was previously widely distributed. European birds were known to leave their breeding areas in autumn and to return in spring, although the location of their historical wintering areas is unknown. Could the species' movements be similar to those today of the glossy ibis Plegadis falcinellus and the spoonbill Platalea leucorodia, involving the crossing of the Strait of Gibraltar?

Reintroducing threatened species is an eye-catching approach to saving species maintained in captivity. This has recently been the case for the northern bald ibis in southern Spain, where 257 birds were released during 2004-2011 in the context of a project evaluating the efficacy of different

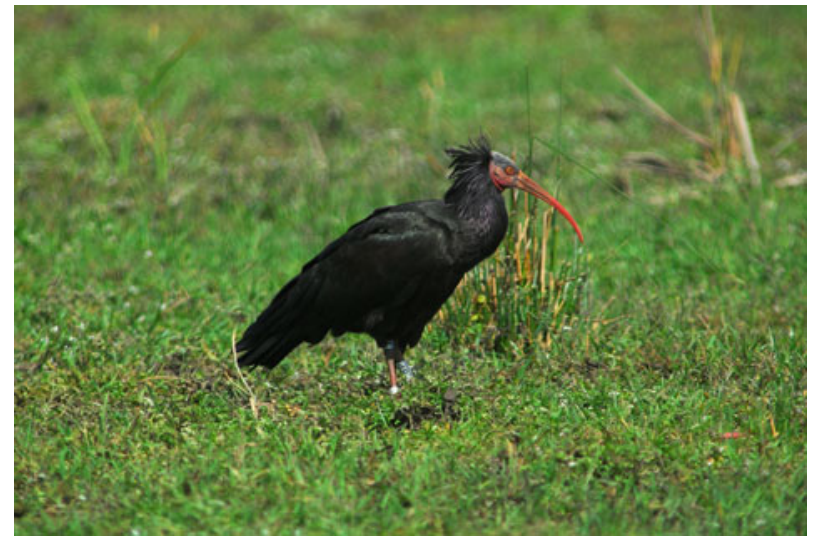

Plate 1 A northern bald ibis Geronticus eremita, ringed and reintroduced in southern Spain, observed in northern Morocco on 24 May 2007 after crossing the Strait of Gibraltar (C) Teo Todorov).

controlled release methods (López et al., 2015, Quercus, $349,15-23)$. In 2008 reproduction in the reintroduced population was confirmed for the first time, and since then the ibises have bred every spring, with a slow increase in numbers.

Here we report the first confirmed sighting of northern bald ibises successfully reaching Morocco after crossing the Strait of Gibraltar, a matter that could have important implications for conservation of this species in an intercontinental area. On 2 November 2016, whilst monitoring migration of the griffon vulture Gyps fulvus, we observed a group of six northern bald ibises reaching the Moroccan coast from Europe. They were first detected at a great distance while flying southwards over the sea, and reached the Moroccan coast at the same point where the arrival of soaring birds was taking place.

Since January 2008 we have regularly visited the wetlands of northern Morocco to survey birds and we have never seen the northern bald ibis there, nor have we received reports of the species. The Moroccan breeding colonies of the northern bald ibis are c. $700 \mathrm{~km}$ south of our observation point.

To our knowledge this is the first observation of a group of northern bald ibises successfully reaching Morocco after crossing from Spain. The only other observation was of a single Spanish-ringed northern bald ibis on 24 May 2007 (Plate 1), in Merja Bargha (116 km south-west of our observation location, in a coastal wetland; Teo Todorov, pers. comm.). These observations suggest that the reintroduced ibises are expanding their home range southwards, which could indicate a progressive adaption of the population.

With the Spanish population increasing, the crossing of the Strait of Gibraltar, in both directions, will probably become more regular, and could have far-reaching consequences for both the Moroccan wild population and for the reintroduction programme in Spain. Many questions require investigation: Will these ibises return to Spain? 
Where are their staging areas in Morocco? Is Morocco acting as a sink for the Spanish population? Could these dispersal movements be the start of new breeding colonies in northern Morocco? Most importantly, could these birds contact the unique and isolated wild colonies in southern Morocco and interbreed with them? Considering the precarious conservation status of the northern bald ibis, and the severe environmental impacts northern Morocco is suffering, it is time to commence cross-border collaboration and conservation action for this Critically Endangered species.

Antonio-RomÁn Muñoz and JuAN RAmírez Departamento de Botànica, Facultad de Farmacia, Universidad de Valencia, Valencia,Spain.E-mail roman@uma.es

\section{Discovery of a second population of the Critically Endangered Madagascan suicide palm Tahina spectabilis}

Researchers from the Royal Botanic Gardens, Kew, the Parc Botanique et Zoologique de Tsimbazaza, and the University of the Sunshine Coast, Australia, have discovered a new site for the Critically Endangered palm Tahina spectabilis. With its nearest living relatives in Asia and the Middle East, the discovery and publication of Tahina (Dransfield et al., 2008, Botanical Journal of the Linnean Society, 156, 79-91), a new monotypic fan palm genus in Madagascar, stunned the international palm community and intrigued the media (the latter dubbing the species 'the Madagascan suicide palm' as a result of the plant's hapaxanthic life history, whereby adults die after flowering).

Tahina spectabilis can reach up to $18 \mathrm{~m}$ in height, with leaves up to $5 \mathrm{~m}$ across, and the crown of the palm is so large that individuals can be seen in images on Google Earth. With fewer than 30 trunked individuals recorded in the wild, at a geographically restricted and vulnerable site on a remote peninsula in north-west Madagascar, T. spectabilis is categorized as Critically Endangered on the IUCN Red List. It is not understood what triggers the species' rare flowering events, but when the palm does flower, it has the capacity to produce enormous numbers of propagules. Kew worked with the local cashew plantation company VERAMA and the local community to collect seed from a successful fruiting event in 2007 and these were sold internationally, with the funds returning to the community to fund conservation and development activities at the site.

Ten years on, a Kew expedition set off in September 2016, with the support of the Mohamed bin Zayed Species Conservation Fund, to re-census the known T. spectabilis population and check on the progress of the conservation work. The team found that, although the population at the original site is still small, it is stable and probably increasing slowly, with nearly 700 individuals recorded. Five adults have flowered and died since the last census in 2008, but another five juvenile individuals have grown sufficiently to be classed as adults. The local community have been protecting the site, with a wide firebreak maintained around the population, and fences built to keep grazing zebu from trampling young plants. At a site nearby, the team found 170 seedlings, and the local community has agreed to monitor and protect this site as well. Income from seed sales has been managed by VERAMA, and has funded several infrastructure projects, including the construction of a school and the digging of a well for the village, and provided ongoing annual funding for the maintenance of the firebreak and fences.

After visiting the original type location of Tahina, the Kew expedition investigated reports of another population of T. spectabilis further inland, just $10 \mathrm{~km}$ from Madagascar's Route National 6 that connects the capital Antananarivo with Ambanja in the north. With the help of local people a small, but unmistakable, group of 25 individuals was discovered in a remote fragment of forest, including five adults, the largest being a medium-sized adult c. $12 \mathrm{~m}$ in height. Initial discussions with the local community about the importance of the species' conservation went well. A follow-up trip in October by another Kew team reinforced and continued these initial discussions, and investigated the needs of the community and how conservation and development work could be brought together at this new site. It is hoped that funding will soon be secured to help with the early stages of this work.

A demographic and genetic study across the two populations and a species conservation management plan are now being prepared. Species distribution models will be run using the currently known geographical range of $T$. spectabilis, and the results used to identify and explore other sites where the species could potentially grow. Although it is highly significant that a second Tahina population exists, it is unlikely that the Red List status of T. spectabilis will change as a result of this new discovery. Even with a much larger Extent of Occurrence for the species, the number of mature individuals known in the wild still remains extremely low at only 34 , and therefore T. spectabilis remains Critically Endangered according to the IUCN Red List Criterion D.

LaURen M. Gardiner Royal Botanic Gardens, Kew, Richmond, Surrey, UK. E-mail l.gardiner@kew.org

DAVID RABEHEVITRA Kew Madagascar Conservation Centre, Ivandry, Antananarivo, Madagascar

Rokiman Letsara Parc Botanique et Zoologique de Tsimbazaza / California Academy of Sciences-Madagascar, Antananarivo, Madagascar 